\title{
Diclazuril-Induced Expression of CDK-Related Kinase 2 in the Second-Generation Merozoites of Eimeria Tenella
}

Bian-hua Zhou ( $\nabla$ zhoubh@haust.edu.cn )

Henan University of Science and Technology https://orcid.org/0000-0003-3811-3898

Hai-yan Ding

Henan University of Science and Technology

Jing-yun Yang

Henan University of Science and Technology

Jun Chai

Luoyang Polytechnic

Hong-wei Guo

Henan University of Animal Husbandry and Economy

Er-jie Tian

Henan University of Science and Technology

Research article

Keywords: CRK2, Diclazuril, cell cycle, Eimeria tenella

Posted Date: August 14th, 2020

DOl: https://doi.org/10.21203/rs.3.rs-28965/v1

License: (1) This work is licensed under a Creative Commons Attribution 4.0 International License.

Read Full License 


\section{Abstract}

Background冈Coccidiosis caused by Eimeria tenella infection, directly or indirectly leads to great loss to poultry industry. With the emergence of drug-resistance in chicken coccidia, it is imperative to develop new drugs. Cyclin-dependent kinases (CDKs) regulate cell cycle progression in numerous organisms by acting as key molecular switches.

Results: In the present study, a diclazuril anticoccidiosis animal model was established and CDK-related kinase 2 (CRK2) in the second-generation merozoite of E. tenella (EtCRK2) gene was amplified through reverse transcription-polymerase chain reaction (RT-PCR) and expressed in Escherichia coli Rosetta (DE3). Purified recombinant protein was used for antiserum preparation. Subsequently, EtCRK2 transcription and translation levels were detected through quantitative real-time PCR and Western blot analysis, respectively. The localization of EtCRK2 in merozoites was examined via immunofluorescence techniques. Results showed that the mRNA and protein expression levels of EtCRK2 decreased in the infected/diclazuril group compared with those in the infected/control group. In addition, immunofluorescence analysis showed that EtCRK2 was localized in the cytoplasm of merozoites. The fluorescence intensity of EtCRK2 in the infected/diclazuril group was significantly weaker than that in the infected/control group.

Conclusions: This study demonstrated that the anticoccidial drug diclazuril against $E$. tenella by affecting the expression pattern of EtCRK2 molecule, and EtCRK2 may be used as a candidate target for new drug development.

\section{Background}

Eimeria tenella is an obligate intracellular parasite that must invade chicken cecal epithelial cells to keep survive and complete the lifecycle. This parasite causes a serious form of coccidiosis and huge economic losses to the poultry community [1]. The prevention and control of coccidiosis mainly rely on ionophores and synthetic chemicals. However, coccidial resistance is induced by the long-term use of anticoccidial drugs [2]. Therefore, new drug targets and control strategies must be sought.

E. tenella has a complex lifecycle that involves an asexual stage (sporogony and schizogamy) and sexual stage (gametogony) [3]. During schizogamy, the E. tenella proliferates within host cells at a high division rate [4], this process is similar to cell cycles in other eukaryotes regulated by cyclin-dependent kinase (CDKs) [5]. CDKs are a kind of serine/threonine kinases that regulate the activity of substrate proteins through phosphorylation [6,7], which regulates cell cycle progression, proliferation, and differentiation and modulate transcription [8-11]. CDK2 plays a pivotal role in regulating G1/S and S/G2 transitions during the cell cycle $[12,13]$. Several CDK-like kinases have been identified and characterized in parasitic protozoans. Toxoplasma gondii CRK1 (TgCRK1), TgCRK2, TgCRK4 and TgCRK6 are essential for tachyzoite replication and growth [14]. Plasmodium falciparum CDK-related kinase 3 (PfCRK-3) fulfills a key role in the intraerythrocytic development of $P$. falciparum [15]. MA Speranca, et al. [16] study 
showed that plasmodial CRK2 gene expression product can interfere with the progress of the wellconserved eukaryotic cell cycle. Theileria annulata CRK3 may be a regulator in gene transcription [17]. CDK2 is involved in differentiation of Giardia lamblia into cysts [8]. CDK-related kinase 2 (EtCRK2) is only $\mathrm{CDK}$ that has been confirmed in $E$. tenella. It is expressed during the asexual and sexual states of $E$. tenella development $[5,18]$.

Diclazuril, a classic anticoccidial drug, significantly induces merozoites apoptosis and effectively decreases the number of merozoites and alleviates the damage in the cecum induced by E. tenella [1924]. Here, we reported the changes in EtCRK2 in response to diclazuril treatment against $E$. tenella infection. In addition, the expression levels of EtCRK2 mRNA and protein and the spatial location of EtCRK2 were observed in the present study.

\section{Results}

\section{Cloning of the EtCRK2 gene}

The 1015 bp EtCRK2 gene was amplified from the second-generation merozoites and cloned into pMD19T vector. A DNA fragment of EtCRK2 ORF amplified from pMD-19-EtCRK2 was subcloned into pET-28a $(+)$. The recombinant plasmid pET-28a-EtCRK2 was analyzed through PCR with pET-28a (+) vector universal primers, and the product length is in according with ORF $891 \mathrm{bp}$ plus vector sequence $360 \mathrm{bp}$ (Fig. 1). At the same time, the insertion 891 bp ORF was also indicated by EcoR I and Hind III enzyme digestion (Fig. 2) and sequenced for $100 \%$ correctness.

\section{Expression of recombinant EtCRK2 protein and polyclonal preparation}

The expressed of the rEtCRK2 protein was induced at $37^{\circ} \mathrm{C}$ with $0.5 \mathrm{mM}$ IPTG for $4 \mathrm{~h}$, to get to high expression and separated through SDS-PAGE (Fig. 3). The theoretical molecular weight rEtCRK2 protein was approximately $37.67 \mathrm{kDa}$. Purified rEtCRK2 protein (Fig. 4) was used antibody preparation. The antiserum has a specific binding with the recombinant protein (Fig. 5) and the titer of antibody against rEtCRK2 exceeded 1:512K (Fig. 6).

\section{Expression of EtCRK2 mRNA}

Fig. 7 showed that compared with that in the infected/control group, the mRNA expression level of EtCRK2 in the infected/diclazuril group was downregulated by $42.3 \%(P<0.01)$.

\section{Western blot analysis}

As shown in Fig. 8, the EtCRK2 protein expression level in the infected/diclazuril group was downregulated by $59.32 \%(P<0.01)$ relative to that in the infected/control group.

\section{Immunofluorescence analysis}


The subcellular location of EtCRK2 in the second-generation merozoite was visualized through immunofluorescence microscopy. As shown in Fig. 9, EtCRK2 was widely distributed in the cytoplasm of merozoites. The green fluorescence in the merozoites of the infected/diclazuril group was darker than that in the merozoites of the infected/control group.

\section{Discussion}

Coccidiosis caused by the apicomplexan parasites of the genus Eimeria induces high economic problem by lowering poultry productivity and performance [25]. E. tenella is one of the most virulent species of Eimeria, which mainly infects chicken cecum. During second-generation schizogony, large amounts of released second-generation merozoites reinvasion other uninfected cecal epithelial cells. Therefore, inhibiting the reproductive process of second-generation merozoites may be an effective strategy to control coccidiosis.

E. tenella utilize complex and distinctive mechanisms to regulate their replicative cycles [14]. CDKs participates in mediating the cell proliferation and division of the parasite [7, 26-28]. In Plasmodium berghei, CRK2 mRNA is expressed richly in gametocytes and mosquito endophase; this characteristic suggests that CRK2 protein has a key role throughout the life cycle [29]. In the schizont stage, the inhibition of $P$. falciparum Cdc2-related kinase-1(PfCRK-1) protein interferes with the growth of $P$. falciparum [30], and the depletion of Plasmodium-specific kinase PfCRK4 result in the complete blockage of nuclear division and intensively inhibits DNA replication [31]. The downregulation of $P$. falciparum M015-related protein kinase (PfMRK), Cdc2-related kinase PfPK5, $P$. falciparum CRK3 and other cyclins during dormancy arrests parasite progression at the $\mathrm{G} 1$ phase, and halts DNA synthesis [32]. The inhibition of CDK7 kinase causes transcript dysregulation in T. gondii [33]. P Mitra, et al. [34] reported that T. gondii CRK9 regulates RNA polymerase II by phosphorylating the $T$. gondii riboflavin binding protein 1 carboxyl-terminal domain. The loss of cytoplasmic TgCRK2 results in T. gondii cell cycle G1 phase arrest [14]. CDK2 participates in intraerythrocytic development of Babesia bovis [35]. These results suggest that CDKs are important molecular switches that contribute to cell cycle progression in parasite [30]. In this study, the levels of EtCRK2 mRNA and protein in the infected/diclazuril group was decreased relative to those the infected/control group. The results indicate that diclazuril blocks merozoites in the $\mathrm{G} 1$ phase by interfering with EtCRK2 pathway, thus preventing the normal reproductive cycle of E. tenella and subsequently decreasing the number of second-generation merozoites [19].

The spatial distribution of proteins is also involved in the performance of protein function. The localization of $T$. annulata CRK2 protein located in the parasite nuclei upregulated transiently in midmerogony. This phenomenon suggests that TaCRK2 is likely to coordinate the parasite's [17]. The protozoan G. Iamblia CDK2 localized in the cytoplasm participate in the cytoplasm participates in the increase in cyst formation and shows increased expression during encystation [8]. The members of $P$. falciparum CDK-like kinase (CLK) family, PfCLk-1 and PfCLK-2, are primarily localized in the nucleus, and the further dispersion of PfCLK-2 into the cytoplasm, indicates that PfCLKs participate in gene regulation via the post-transcriptional modification of mRNA in the malaria blood stage [36]. In the present study, 
EtCRK2 was found to be localized in the cytoplasm of second-generation merozoite. Under diclazuril treatment, the fluorescence intensity of EtCDK2 decrease. This phenomenon is consistent with the determined expression levels. These results implied that EtCRK2 play an essential role in the asexual life cycle of $E$. tenella, indicating that agents targeting CRK2 may be potential therapeutic strategies against coccidiosis.

\section{Conclusion}

The results in the present study demonstrate for the first time that the diclazuril likely downregulate the mRNA and protein expression of EtCRK2 and disturb the cell cycle of the second-generation merozoites. This action may be an aspect of the molecular mechanism of the anticoccidial action of diclazuril.

\section{Methods}

\section{Inoculum and Drug}

Ocysts of E. tenella (Luoyang strain) were passaged before inoculation. Diclazuril (>99\%) (Shanghai Veterinary Research Institute, CAAS, China) was supplied at a dose of $1 \mathrm{mg} / \mathrm{kg}$ in broiler feed.

\section{Chickens and Treatment}

1-day-old male Chinese Yellow broiler chickens were obtained from Gonghua Commercial Hatchery, Luoyang, China. The chickens were kept on wire-floored batteries for 14 days under coccidiosis-free conditions. On the $14^{\text {th }}$ days, healthy 90 chickens with similar weight were randomly divided into two groups of 45 with 3 biological replicates of 15 in each group: (1) Chickens that were challenged with $E$. tenella sporulated oocysts and that received commercial diet without drugs were designated as the infected/control group. (2) Chickens that were challenged with E. tenella sporulated oocysts and treated with $1 \mathrm{mg} / \mathrm{kg}$ diclazuril in feed from $96 \mathrm{~h}$ to $120 \mathrm{~h}$ were designated as the infected/diclazuril group. Inoculation was performed with a dose of $8 \times 10^{4}$ sporulated oocysts/chicken on days 14 . The experimental scheme conformed strictly to the guidelines of the Institutional Animal Care and Use

Committee (No. 201) of Henan University of Science and Technology (Luoyang, Henan, China).

\section{Preparation of the Second-generation Merozoites}

At $120 \mathrm{~h}$ post inoculation, chickens killed by $\mathrm{CO}_{2}$ asphyxiation, cecal tissues from randomly selected 10 chickens pooled in each replicate were used for preparation of the second-generation merozoites in accordance with our previously described method [19-21]. The collected merozoites samples were subjected for RNA preparation, Western blot and immunofluorescence assay, respectively. Thus, there were three samples in each group for each experiment.

\section{Total RNA Preparation and cDNA Synthesis}


In accordance with the manufacturer's procedure, the total RNA of merozoites was extracted with TRIzol ${ }^{\circledR}$ Reagent (Invitrogen, USA), and cDNA was synthesized by using EasyScript One-Step gDNA Removal and cDNA Synthesis SuperMix (TransGen Biotech, Beijing).

\section{Amplification of EtCRK2 Gene}

Based the sequence form GenBank: AY508221.1, specific primers P1: 5'-AAGGGACTTACGGAGTGGTTTA3' and P2: 5'-TGAATTTACGTGAATATGTTGG-3' were used to amplify EtCRK2 gene including an open reading frame (ORF) from a cDNA template. Amplified fragments were separated through $1 \%$ agarose gel electrophoresis and isolated using the TaKaRa MiniBEST Agarose Gel DNA Extraction Kit Ver.4.0 (Takara, Beijing) following the manufacturer's instructions. The purified amplifying fragments were ligated into the pMD-19T vector (Takara, Beijing), and then transformed into Escherichia coli strain DH5a (Takara, Beijing). The recombinant clone of pMD-19-EtCRK2 was identified through polymerase chain reaction (PCR) and sequenced by Sangon Biotech (Shanghai) Co., Ltd. The positive plasmid was named pMD-19EtCRK2.

\section{Prokaryotic Expression and Purification of EtCRK2}

Using positive pMD-19-EtCRK2 as template, the ORF of EtCRK2 was amplified using primers containing EcoR I (P2-F: 5'-CGGGAATTCATGGAGCGCTACAAGA-3') or Hind III (P2-R: 5'-

TCTTGTAGCGCTCCATGAATTCCCG-3') restriction sites. Amplification products and pET-28a (+) were digested by EcoR I and Hind III prior to ligation. The recombinant plasmid pET-28a-EtCRK2 was transformed into E. coli Rosetta (DE3) competent cells that were induced at $37^{\circ} \mathrm{C}$ with $0.5 \mathrm{mM}$ IPTG. Recombinant EtCRK2 ( $r E t C R K 2)$ protein was purified through Ni-NTA His Bind Resin affinity chromatography (Novagen, Germany) and then analyzed using sodium dodecyl sulfate polyacrylamide gel electrophoresis (SDS-PAGE).

\section{Polyclonal Antibody Preparation}

To produce polyclonal antibody, purified rEtCRK2 protein was used as antigen in the following immune procedures. rEtCRK2 protein emulsified with the same volume of Freund's complete adjuvant (SigmaAldrich) was injected into New Zealand rabbits at a dose of $500 \mathrm{mg} /$ rabbit. After 2 weeks, purified rEtCRK2 protein emulsified with Freund's incomplete adjuvant (Sigma-Aldrich) was injected to the rabbits at a dose of $500 \mathrm{mg} / \mathrm{rabbit}$ for secondary immunization. Then, at the interval of a 2-week hiatus, the third and fourth immunizations were performed separately. Ten days after the last immunization, serum samples were collected and determined by indirect enzyme linked immunosorbent assay (ELISA) [37].

Briefly, $500 \mathrm{ng} /$ well recombinant protein was used to coat the 96 -well plates at $4{ }^{\circ} \mathrm{C}$ overnight, the antiserum were diluted with PBS at 1:2K, 1:4K, 1:8K, 1:16K, 1:32K, 1:64K, 1:128K, 1:256K, 1:512K, $1: 1024 \mathrm{~K}, 1: 2048 \mathrm{~K}$, and then incubated with antigens at $37^{\circ} \mathrm{C}$ for 2 hours. After washing by TBST, Horse Radish Peroxidase (HRP)-conjugated goat anti-rabbit IgG were added to all microwells at $37^{\circ} \mathrm{C}$ for 2 hours. After washing, the substrate solution tetra-methyl ben-zidine (TMB) was added and the microplate was read at $450 \mathrm{~nm}$ in a microplate reader (Multiskan FC, Thermo Scientific, USA). Preimmunization 
rabbit serum and PBS were used as the control. The specificity of antibody was determined by Western blot, briefly, $25 \mathrm{ng}$ recombinant protein was used for loading for SDS-PAGE, preimmunization rabbit serum and antiserum was used as the primary antibodies followed by HRP conjugated goat anti-rabbit IgG (Biolab, Beijing). HRP activity was revealed by enhanced chemiluminescence system using BeyoECL Plus substrate (P0018S, Beyotime Biotechnology, China)

\section{EtCRK2 mRNA Expression Analysis}

The mRNA expression level of EtCRK2 was quantified through real-time PCR using the CFX96 touch realtime PCR system (Bio-Rad, America) and TB Green ${ }^{\circledR}$ Premix Ex Taq ${ }^{\text {TM }}$ GC (Perfect Real Time) (Takara, Beijing). Each reaction was performed in triplicate, and the entire experiment was carried out in triplicate. E. tenella 18S rRNA was used as the control. The primer sequences are shown in Table 1. Relative mRNA expression was determined by using the ${ }^{\Delta \Delta} \mathrm{Ct}$ method.

\section{Western Blot Assay}

Purified merozoites were treated with RIPA lysis buffer (Beyotime, Shanghai) for Western blot analysis and determined by BCA Protein Assay Kit (Cwbio, Beijing) for concentration assessment. Pyrolysis products were dissolved in SDS-PAGE sample buffer (Beyotime, Shanghai), heated at $96{ }^{\circ} \mathrm{C}$ for $5 \mathrm{~min}$, separated on $12 \%$ SDS-PAGE, and then electrotransferred to a polyvinylidene difluoride membrane (Membrane Solutions, USA). The membrane was detected with rabbit antiserum against EtCRK2 as the primary antibodies or anti- $\beta$-tubulin monoclonal antibody (1:1000 dilution, K200059 M, Solarbio, China), followed by HRP conjugated goat anti-rabbit IgG (Biolab, Beijing). HRP activity was revealed by enhanced chemiluminescence system using BeyoECL Plus substrate (P0018S, Beyotime Biotechnology, China) and Image J Software. The independent experiments were performed in triplicate.

\section{Immunofluorescence Test}

In accordance with our previously described method with minor modifications [22], the merozoites were prepared into smears and fixed with $4 \%$ paraformaldehyde. After washing three times with PBS, the merozoites were permeabilized with 1\% Triton X-100 (Sangon-Biotech, Shanghai) and blocked with 2\% BSA-PBS. Rabbit antiserum against EtCRK2 (1:2000 dilution) was used as the primary antibody, and FITC-conjugated goat anti-rabbit IgG (Servicebio, Wuhan) with 1:100 dilution was used as the second antibody. Finally, the merozoites were stained with 4',6'-diamidino-2-phenylindole (DAPI) (Boster, China). Images were visualized with a confocal laser scanning microscope (LSM 800, ZEISS) at an $\mathrm{I}_{\mathrm{ex} / \mathrm{em}}$ of 492 $\mathrm{nm} / 520 \mathrm{~nm}$ and $358 \mathrm{~nm} / 461 \mathrm{~nm}$, respectively.

\section{Statistical Analysis}

Data were expressed as mean \pm standard deviation. Student's $t$ test was used for statistical analyses. Values of $P<0.05$ and $P<0.01$ were considered significant. 


\section{Abbreviations}

CDK

Cyclin-dependent kinases; CRK:CDK-related kinase; PCR:Polymerase chain reaction; bp:base pair; ORF:Open reading frame; IPTG:Isopropyl-b-D-thiogalactopyranoside; SDS-PAGE:Sodium dodecyl sulfatepolyacrylamide gel electrophoresis; kDa:Kilodalton; ELISA:indirect enzyme linked immunosorbent assay. PBS:Phosphate buffer saline; TBST:Tris-Buffered Saline containing 0.05\% Tween 20;

TMB:Tetramethylbenzidine; BSA:Bovine serum albumin; FITC:Fluoresceine isothiocyanate; $E$. tenella: Eimeria tenella; T. gondii: Toxoplasma gondii; $P$. falciparum: Plasmodium falciparum; $P$. berghei:Plasmodium berghei.

\section{Declarations}

\section{Ethics approval and consent to participate}

Animals housing and care complied with the Guide for Ethical Review of laboratory animal welfare, China (GB/T 35892-2018). The study was approved by the Institutional Animal Care and Use Committee of Henan University of Science and Technology.

\section{Consent for publication}

Not applicable

\section{Availability of data and materials}

The datasets supporting the findings of this article are included within the article.

\section{Competing interests}

No potential conflict of interest was reported by the authors.

\section{Funding}

This research was funded by National Natural Science Foundation of China (Grants Nos. 31101855 and 31472238). This funding body provided monetary support only and did not have any input into the design of the study, collection, analysis, and interpretation of data.

\section{Authors' contributions}

BZ: Software, Validation, Formal analysis, Data Curation, Methodology, Visualization, Writing - Review \& Editing, Funding acquisition. HD: Writing - Original Draf, Visualization, Investigation. JY, JC, HG and ET: Investigation. All authors read and approved the final version of the manuscript.

\section{Acknowledgements}


Not applicable.

Authors' information

${ }^{1}$ College of Animal Science and Technology, Henan University of Science and Technology, Kaiyuan Avenue 263, Luolong District, Luoyang 471023, Henan, People's Republic of China.

2 School of information technology and urban construction, Luoyang Polytechnic, Keji Avenue 6, Yibin District, Luoyang, 471934, Henan, People's Republic of China.

${ }^{3}$ College of Animal Science and Technology, Henan University of Animal Husbandry and Economy, Longzi Hubei Road 6, Zhengzhou 450046, Henan, People's Republic of China.

\section{References}

1. Liu LL, Chen ZG, Mi RS, Zhang KY, Liu YC, Jiang W, Fei CZ, Xue FQ, Li T: Effect of Acetamizuril on enolase in second-generation merozoites of Eimeria tenella. Vet Parasitol 2016, 215:88-91.

2. Tan L, Li Y, Yang X, Ke Q, Lei W, Mughal MN, Fang R, Zhou Y, Shen B, Zhao J: Genetic diversity and drug sensitivity studies on Eimeria tenella field isolates from Hubei Province of China. Parasit Vectors 2017, 10(1):137.

3. Zhou BH, Wang HW, Zhao ZS, Liu M, Yan WC, Zhao J, Zhang Z, Xue FQ: A novel serine/threonine protein phosphatase type 5 from second-generation merozoite of Eimeria tenella is associated with diclazuril-induced apoptosis. Parasitol Res 2013, 112(4):1771-1780.

4. Fernandez MLS, Engels KK, Bender F, Gassel M, Marhofer RJ, Mottram JC, Selzer PM: Highthroughput screening with the Eimeria tenella CDC2-related kinase2/cyclin complex EtCRK2/EtCYC3a. Microbiology 2012, 158(Pt 9):2262-2271.

5. Engels K, Beyer C, Suarez Fernandez ML, Bender F, Gassel M, Unden G, Marhofer RJ, Mottram JC, Selzer PM: Inhibition of Eimeria tenella CDK-related kinase 2: From target identification to lead compounds. ChemMedChem 2010, 5(8):1259-1271.

6. Lim S, Kaldis P: Cdks, cyclins and CKls: roles beyond cell cycle regulation. Development 2013, 140(15):3079-3093.

7. Deshmukh AS, Agarwal M, Dhar SK: Regulation of DNA replication proteins in parasitic protozoans: possible role of CDK-like kinases. Curr Genet 2016, 62(3):481-486.

8. Cho CC, Su LH, Huang YC, Pan YJ, Sun CH: Regulation of a Myb transcription factor by cyclindependent kinase 2 in Giardia lamblia. J Biol Chem 2012, 287(6):3733-3750.

9. Malumbres M: Cyclin-dependent kinases. Genome Biol 2014, 15(6):122.

10. Hydbring P, Malumbres M, Sicinski P: Non-canonical functions of cell cycle cyclins and cyclindependent kinases. Nat Rev Mol Cell Biol 2016, 17(5):280-292.

11. Garcia-Reyes B, Kretz AL, Ruff JP, von Karstedt S, Hillenbrand A, Knippschild U, Henne-Bruns D, Lemke J: The Emerging Role of Cyclin-Dependent Kinases (CDKs) in Pancreatic Ductal 
Adenocarcinoma. Int J Mol Sci 2018, 19(10).

12. Li Y, Zhang J, Gao W, Zhang L, Pan Y, Zhang S, Wang Y: Insights on Structural Characteristics and Ligand Binding Mechanisms of CDK2. Int J Mol Sci 2015, 16(5):9314-9340.

13. Peng C, Zeng W, Su J, Kuang Y, He Y, Zhao S, Zhang J, Ma W, Bode AM, Dong Z et al: Cyclindependent kinase 2 (CDK2) is a key mediator for EGF-induced cell transformation mediated through the ELK4/c-Fos signaling pathway. Oncogene 2016, 35(9):1170-1179.

14. Alvarez CA, Suvorova ES: Checkpoints of apicomplexan cell division identified in Toxoplasma gondii. PLoS Pathog 2017, 13(7):e1006483.

15. Halbert J, Ayong L, Equinet L, Le Roch K, Hardy M, Goldring D, Reininger L, Waters N, Chakrabarti D, Doerig C: A Plasmodium falciparum transcriptional cyclin-dependent kinase-related kinase with a crucial role in parasite proliferation associates with histone deacetylase activity. Eukaryot Cel/ 2010, 9(6):952-959.

16. Speranca MA, Vinkenoog R, Ocampos M, Fischer K, Janse CJ, Waters AP, del Portillo HA: Primary structure of the Plasmodium vivax crk2 gene and interference of the yeast cell cycle upon its conditional expression. Exp Parasitol 2001, 97(3):119-128.

17. Kinnaird J, Logan M, Tait A, Langsley G: TaCRK3 encodes a novel Theileria annulata protein kinase with motifs characteristic of the family of eukaryotic cyclin dependent kinases: a comparative analysis of its expression with TaCRK2 during the parasite life cycle. Gene 2001, 279(2):127-135.

18. Kinnaird JH, Bumstead JM, Mann DJ, Ryan R, Shirley MW, Shiels BR, Tomley FM: EtCRK2, a cyclindependent kinase gene expressed during the sexual and asexual phases of the Eimeria tenella life cycle. Int J Parasitol 2004, 34(6):683-692.

19. Zhou BH, Wang HW, Wang XY, Zhang LF, Zhang KY, Xue FQ: Eimeria tenella: effects of diclazuril treatment on microneme genes expression in second-generation merozoites and pathological changes of caeca in parasitized chickens. Exp Parasitol 2010, 125(3):264-270.

20. Zhou B, Wang H, Xue F, Wang X, Fei C, Wang M, Zhang T, Yao X, He P: Effects of diclazuril on apoptosis and mitochondrial transmembrane potential in second-generation merozoites of Eimeria tenella. Vet Parasitol 2010, 168(3-4):217-222.

21. Zhou BH, Wang HW, Xue FQ, Wang XY, Yang FK, Ban MM, Xin RX, Wang CC: Actin-depolymerizing factor of second-generation merozoite in Eimeria tenella: clone, prokaryotic expression, and diclazuril-induced mRNA expression. Parasitol Res 2010, 106(3):571-576.

22. Zhou BH, Shen XJ, Wang HW, Li T, Xue FQ: Receptor for activated C kinase ortholog of secondgeneration merozoite in Eimeria tenella: clone, characterization, and diclazuril-induced mRNA expression. Parasitol Res 2012, 111(4):1447-1455.

23. Tian EJ, Zhou BH, Wang XY, Zhao J, Deng W, Wang HW: Effect of diclazuril on intestinal morphology and SIgA expression in chicken infected with Eimeria tenella. Parasitol Res 2014, 113(11):4057-4064.

24. Zhou BH, Liu LL, Liu J, Yuan FW, Tian EJ, Wang HW: Effect of Diclazuril on the Bursa of Fabricius Morphology and SIgA Expression in Chickens Infected with Eimeria tenella. Korean J Parasito/ 2015, 53(6):675-682. 
25. Wang X, Zou W, Yu H, Lin Y, Dai G, Zhang T, Zhang G, Xie K, Wang J, Shi H: RNA Sequencing Analysis of Chicken Cecum Tissues Following Eimeria tenella Infection in Vivo. Genes (Basel) 2019, 10(6).

26. Mottram JC, Smith G: A family of trypanosome cdc2-related protein kinases. Gene 1995, 162(1):147152.

27. Roques M, Wall RJ, Douglass AP, Ramaprasad A, Ferguson DJ, Kaindama ML, Brusini L, Joshi N, Rchiad Z, Brady D et al: Plasmodium P-Type Cyclin CYC3 Modulates Endomitotic Growth during Oocyst Development in Mosquitoes. PLoS Pathog 2015, 11(11):e1005273.

28. Deshmukh AS, Mitra P, Kolagani A, Gurupwar R: Cdk-related kinase 9 regulates RNA polymerase II mediated transcription in Toxoplasma gondii. Biochim Biophys Acta Gene Regul Mech 2018, 1861(6):572-585.

29. Vinkenoog R, Speranca MA, Ramesar J, Thomas AW, del Portillo HA, Janse CJ, Waters AP: Characterisation of the Cdc2-related kinase 2 gene from Plasmodium knowlesi and P. berghei. $\mathrm{Mol}$ Biochem Parasitol 1998, 95(2):229-240.

30. Iwanaga T, Sugi T, Kobayashi K, Takemae H, Gong H, Ishiwa A, Murakoshi F, Recuenco FC, Horimoto $\mathrm{T}$, Akashi $\mathrm{H}$ et al: Characterization of Plasmodium falciparum cdc2-related kinase and the effects of a CDK inhibitor on the parasites in erythrocytic schizogony. Parasitol Int 2013, 62(5):423-430.

31. Ganter M, Goldberg JM, Dvorin JD, Paulo JA, King JG, Tripathi AK, Paul AS, Yang J, Coppens I, Jiang $\mathrm{RH}$ et al: Plasmodium falciparum CRK4 directs continuous rounds of DNA replication during schizogony. Nat Microbiol 2017, 2:17017.

32. Gray KA, Gresty KJ, Chen N, Zhang V, Gutteridge CE, Peatey CL, Chavchich M, Waters NC, Cheng Q: Correlation between Cyclin Dependent Kinases and Artemisinin-Induced Dormancy in Plasmodium falciparum In Vitro. PLoS One 2016, 11(6):e0157906.

33. Deshmukh AS, Mitra P, Maruthi M: Cdk7 mediates RPB1-driven mRNA synthesis in Toxoplasma gondii. Sci Rep 2016, 6:35288.

34. Mitra P, Deshmukh AS, Gurupwar R, Kashyap P: Characterization of Toxoplasma gondii Spt5 like transcription elongation factor. Biochim Biophys Acta Gene Regul Mech 2019, 1862(2):184-197.

35. Nakamura K, Yokoyama N, Igarashi I: Cyclin-dependent kinase inhibitors block erythrocyte invasion and intraerythrocytic development of Babesia bovis in vitro. Parasitology 2007, 134(Pt 10):13471353.

36. Agarwal S, Kern S, Halbert J, Przyborski JM, Baumeister S, Dandekar T, Doerig C, Pradel G: Two nucleus-localized CDK-like kinases with crucial roles for malaria parasite erythrocytic replication are involved in phosphorylation of splicing factor. J Cell Biochem 2011, 112(5):1295-1310.

37. Gan SD, Patel KR: Enzyme immunoassay and enzyme-linked immunosorbent assay. J Invest Dermatol 2013, 133(9):e12.

\section{Tables}


Table 1

Primer sequences with their corresponding PCR product size and position

\begin{tabular}{|lllll|}
\hline Gene & Primers $\left(5^{\prime} \rightarrow 3^{\prime}\right)$ & $\begin{array}{l}\text { Primer } \\
\text { locations }\end{array}$ & $\begin{array}{l}\text { Product } \\
\text { (base pairs) }\end{array}$ & $\begin{array}{l}\text { Genbank } \\
\text { Accession no. }\end{array}$ \\
\hline 18S rRNA & ATCGCAGTTGGTTCTTTTGG & $248-417$ & 170 & U67121 \\
& CCTGCTGCCTTCCTTAGATG & & & \\
\hline EtCRK2 & CTAGACGACTGCCGACCTTC & $524-746$ & 223 & AY508221.1 \\
& GGGTTCCGTCTCTGCTTATG & & & \\
\hline
\end{tabular}

\section{Figures}




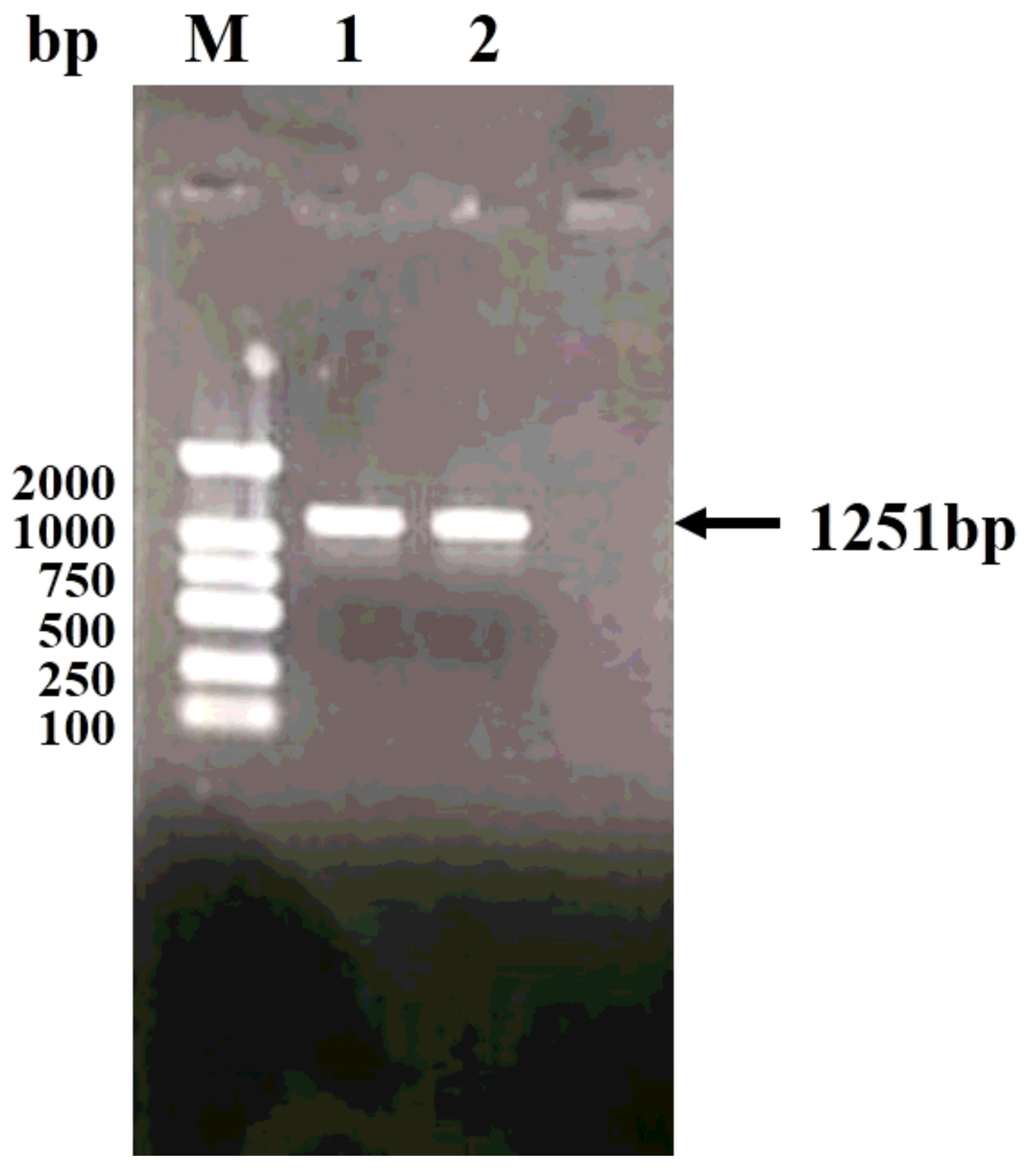

Figure 1

Agarose gel electrophoresis of EtCRK2 gene ORF. M, DL2000 DNA Marker; 1and 2, PCR amplification products via pET-28a (+) vector universal primers. 


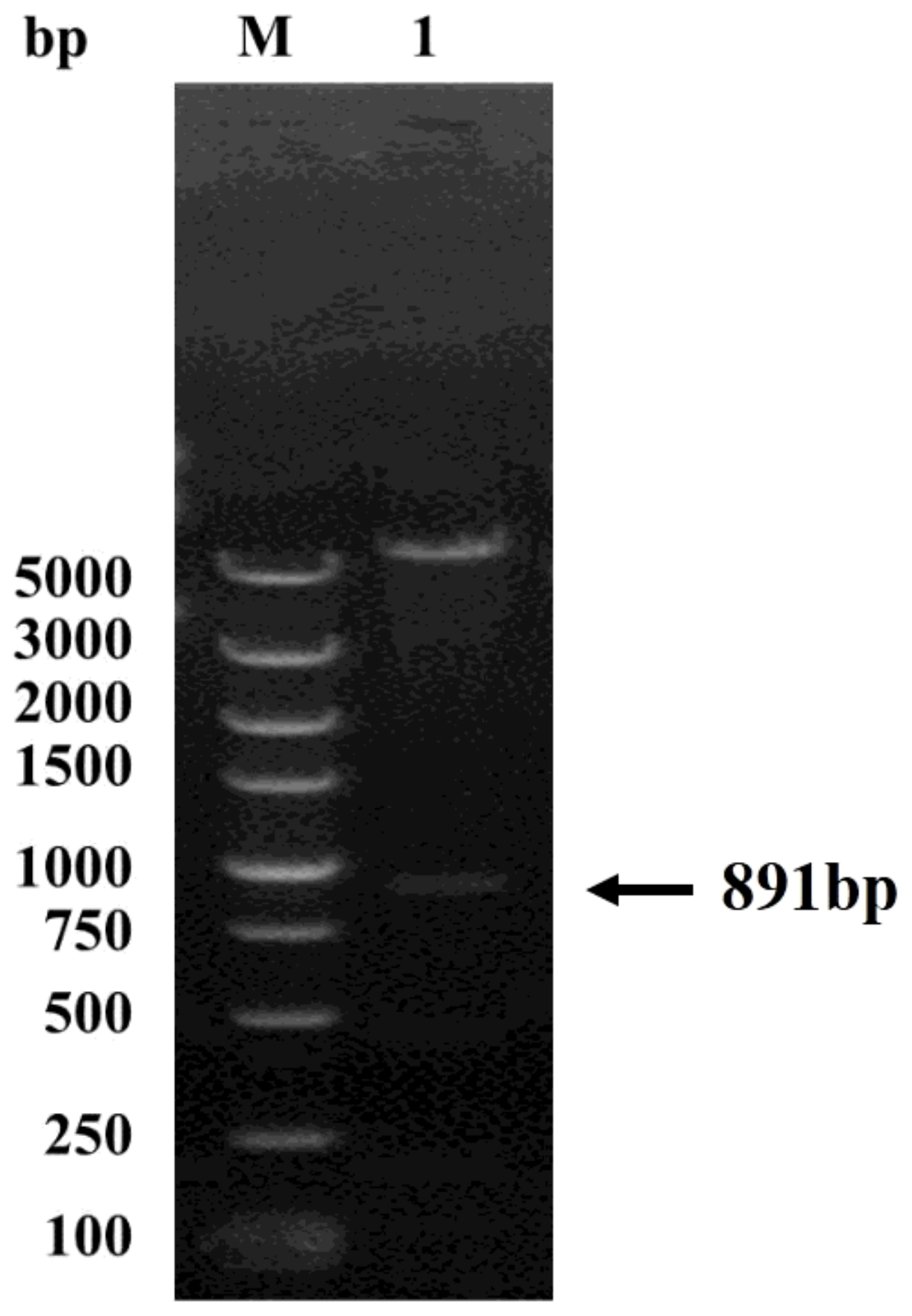

Figure 2

Restriction digestion analysis. M, DL5000 DNA Marker; 1, Plasmid pET-28a-EtCRK2 digested by EcoR I and Hind III. 


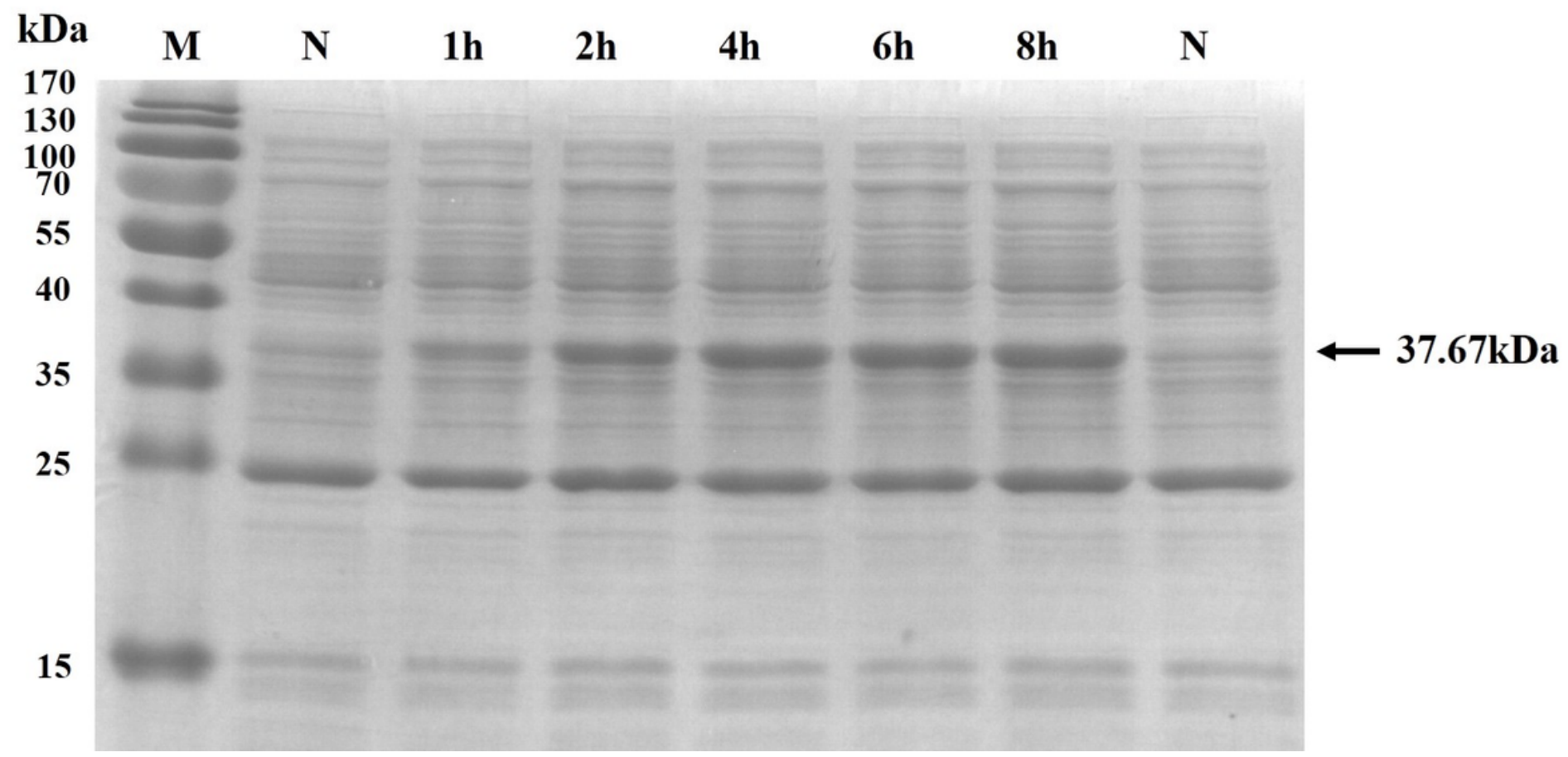

\section{Figure 3}

Induced expression of EtCRK2 fusion protein. M, Protein molecular weight Marker; pET-28a-EtCRK2 were induced expression of 1 h, 2 h, 4 h, 6 h and 8 h, respectively; N, empty pET-28a were induced expression. 


\section{kDa M Pu}

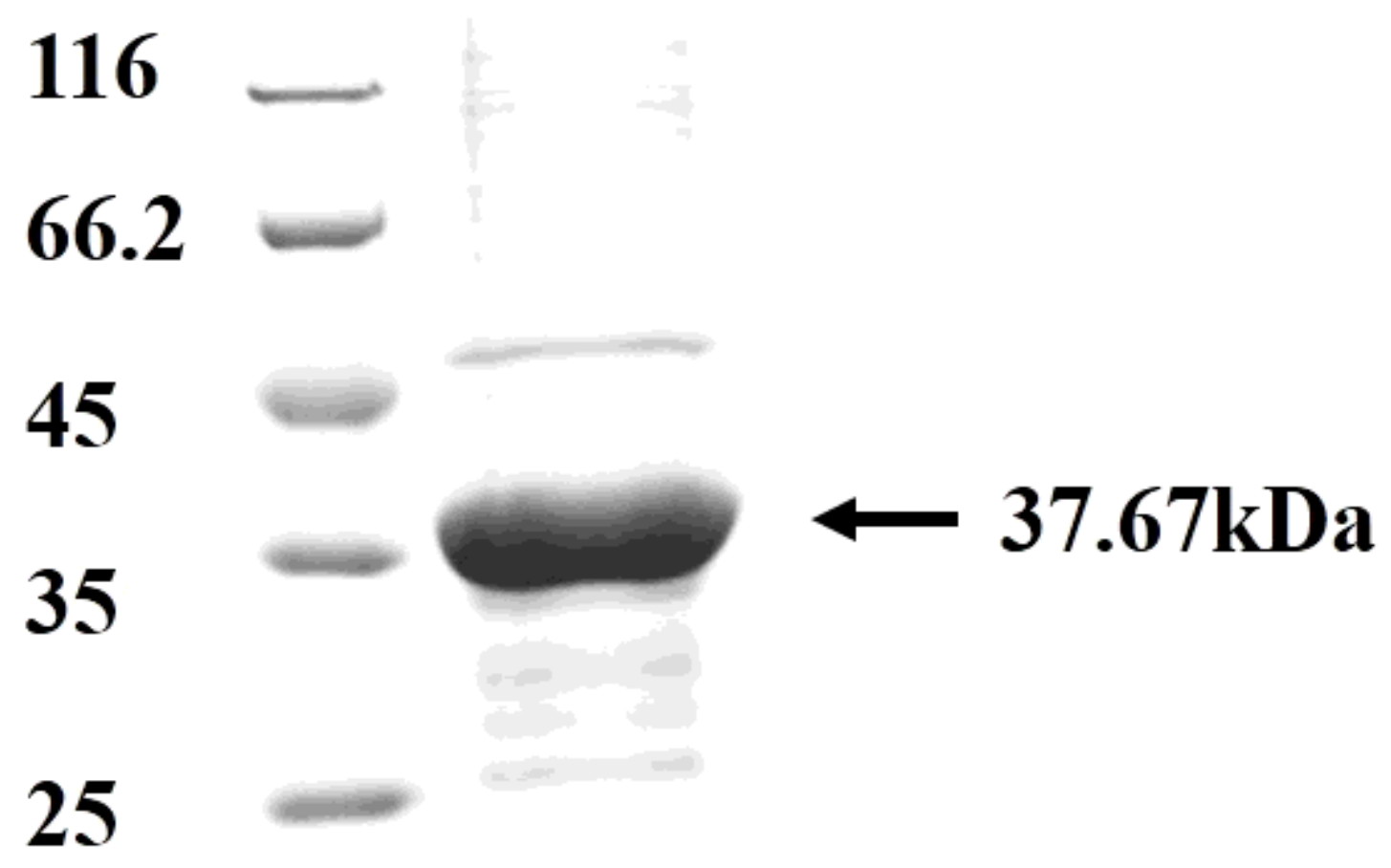

\section{4 \\ 14.4}

Figure 4

Purification of rEtCRK2 protein. M, Protein molecular weight Marker; Pu, purified rEtCRK2 protein. 


\section{KDa M 1212}

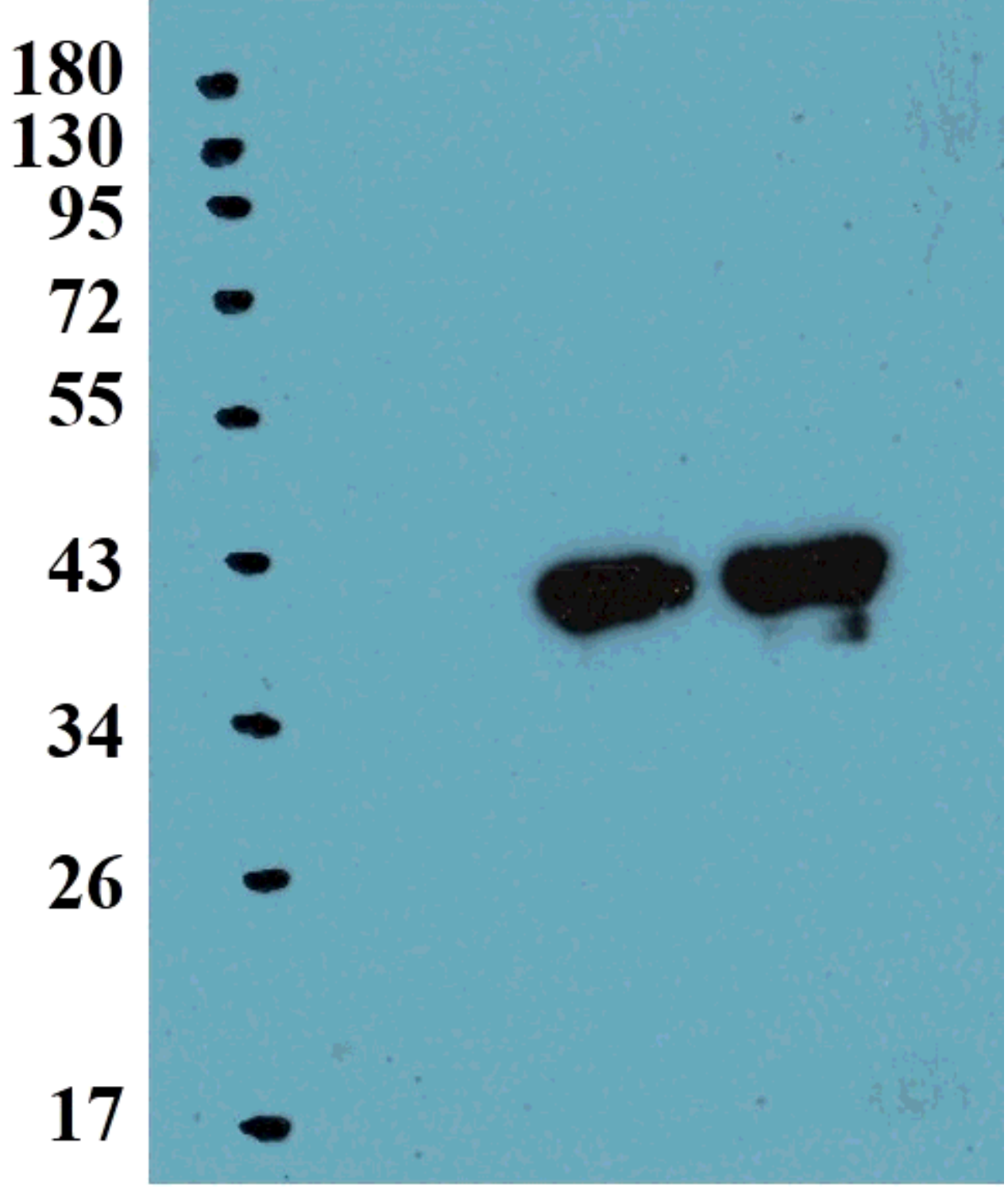

Figure 5

Rabbit-anti-EtCRK2 serum specific binding analysis by Western blot. M, Protein molecular weight Marker; 1, Pre-immunization serum as the first antibody; 2 and 3, antiserum as the first antibody. 


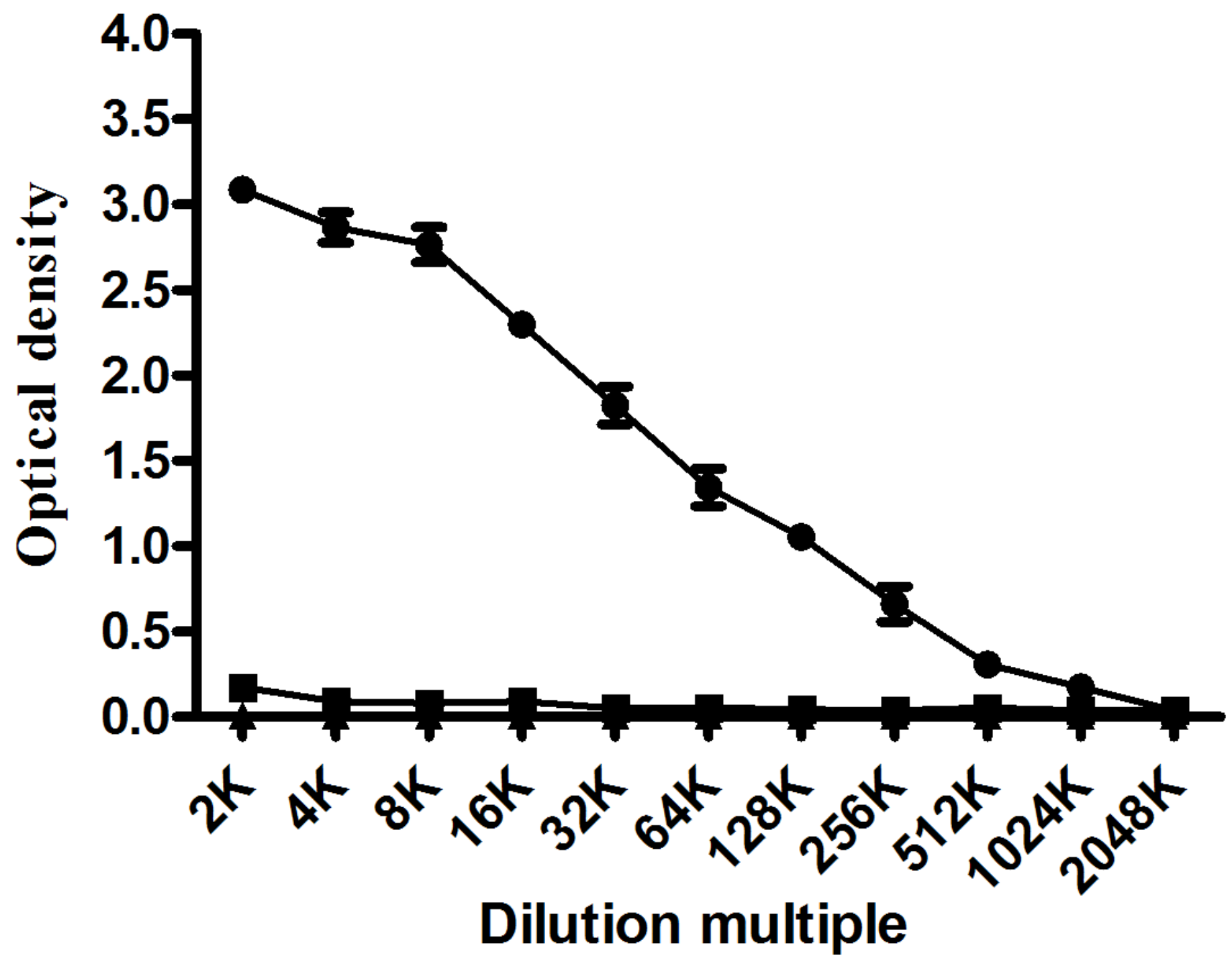

$\rightarrow$ Antiserum

$\rightarrow$ Pre-immunization serum

$\mp$ Negative control

Figure 6

Serum anti-EtCRK2 antibody levels measured by ELISA 


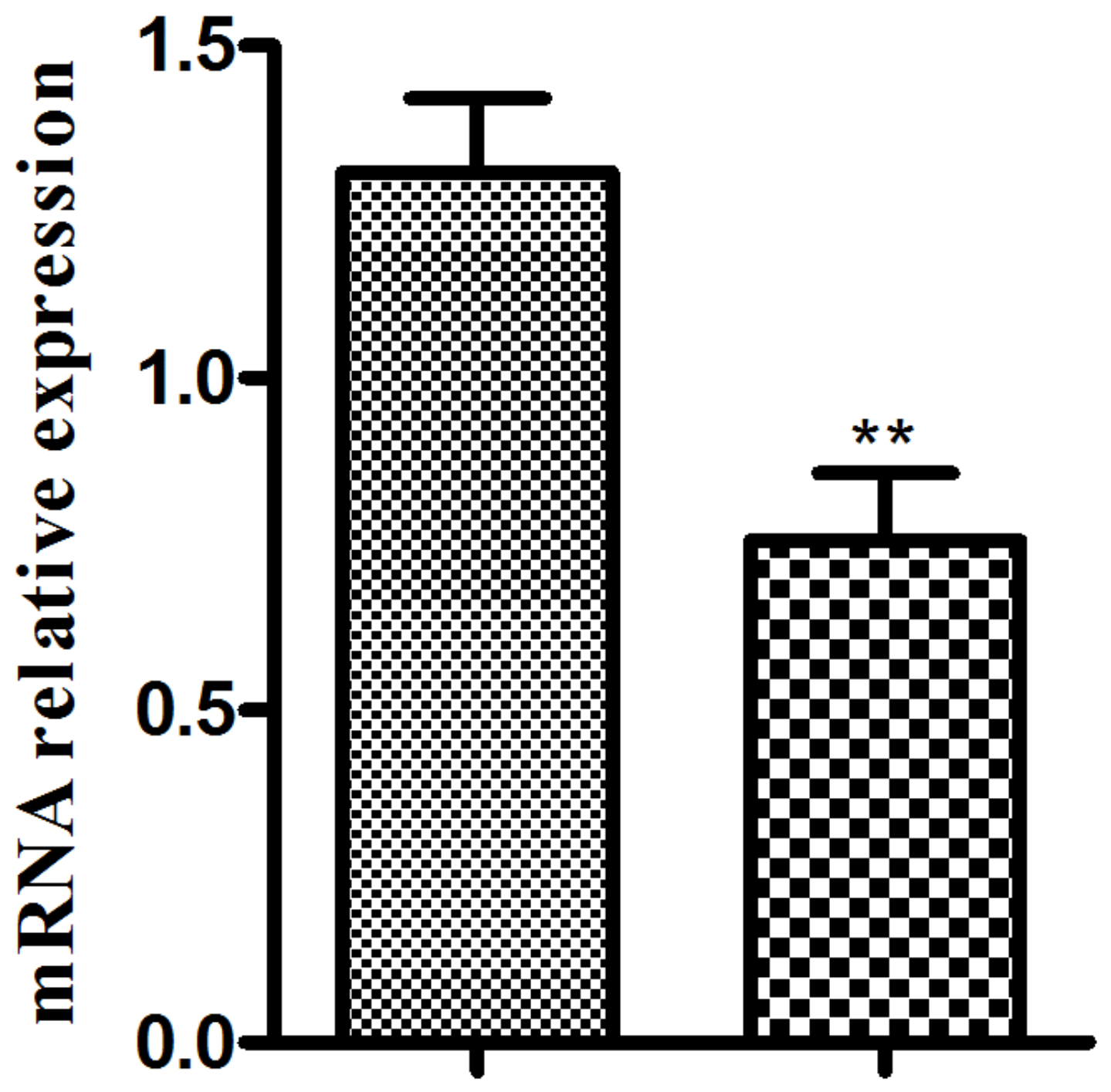

\section{Infected/control group \\ as Infected/diclazuril group}

Figure 7

The mRNA relative expression level of EtCRK2 
A

B

\section{EtCRK2}

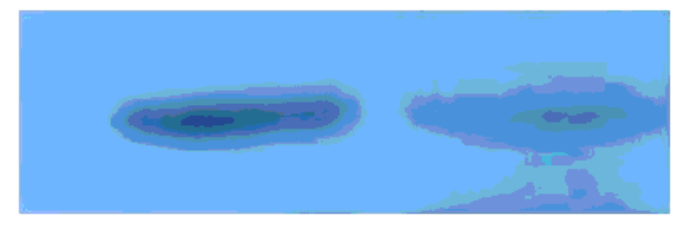

\section{EtTubulin}
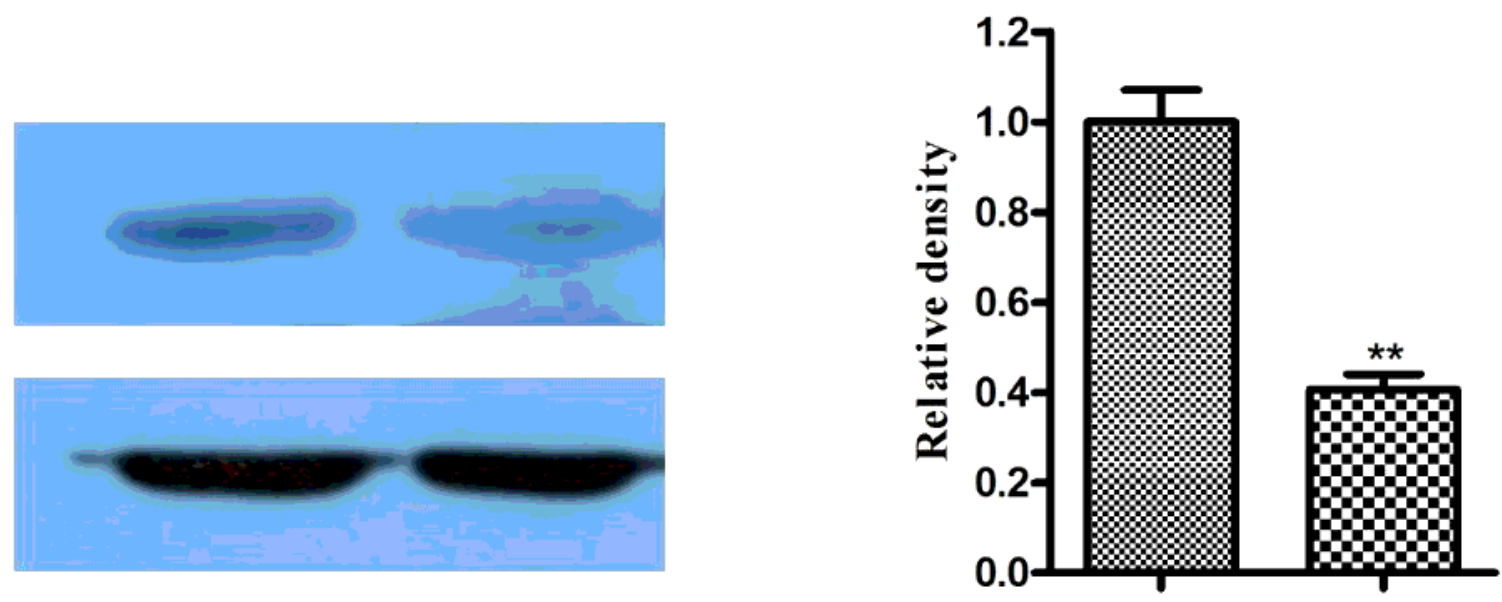

\begin{tabular}{|cc|}
\hline Infected & Infected \\
/control & /diclazuril \\
group & group \\
\hline
\end{tabular}

Infected/control group

B Infected/diclazuril group

Figure 8

Western blot analysis of EtCRK2 protein expression. A, Western blot electrophoretic pattern of EtCRK2 and EtTubulin. B, EtCRK2 relative density. ** $\mathrm{P} \otimes 0.01$ compared with the infected/control group.

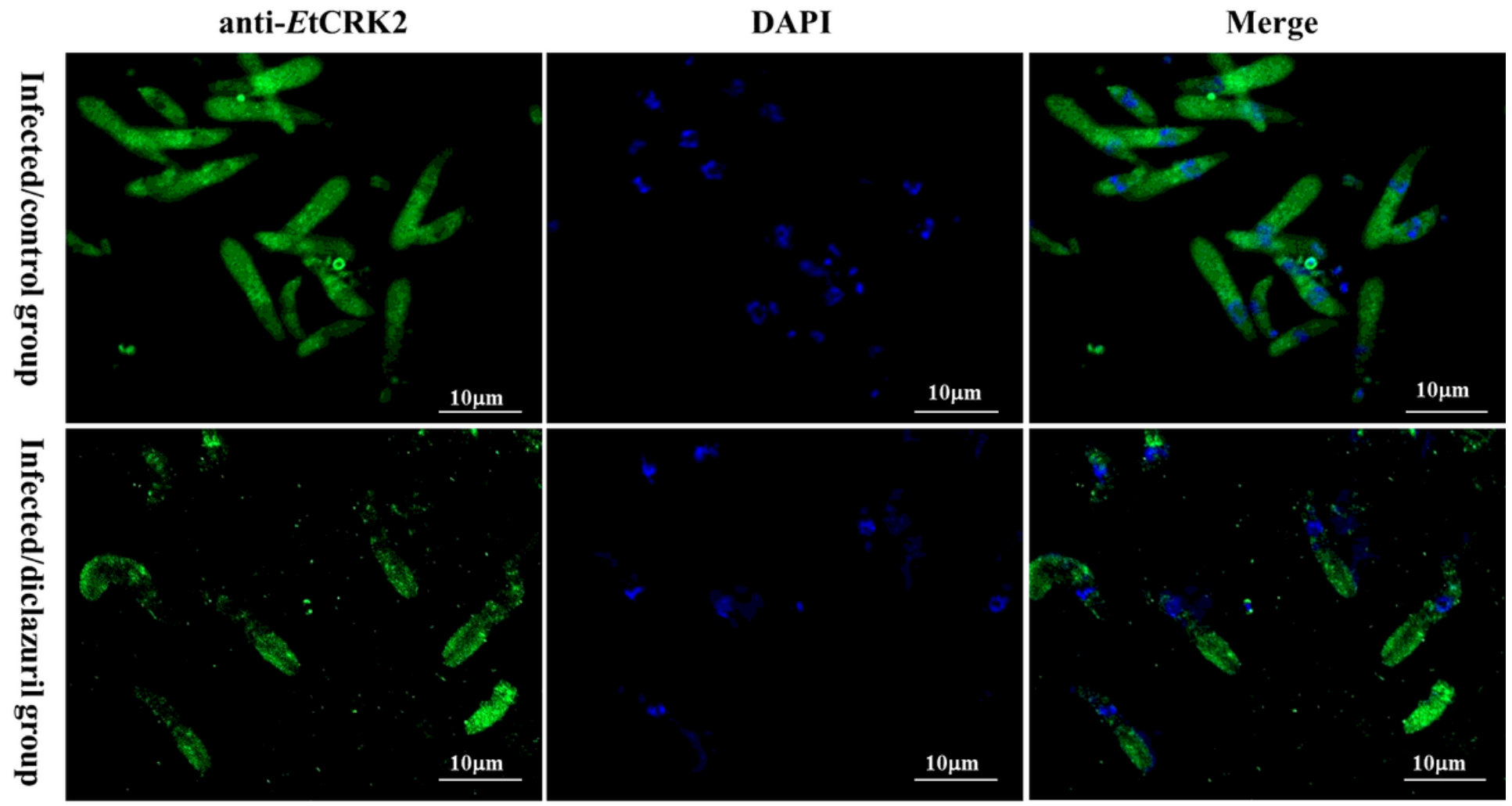

Figure 9 
Localizations of EtCRK2 in second-generation merozoites. EtCRK2 is widely distributed to the cytoplasm in merozoite. Compared with the infected/control group, the EtCRK2 immunostaining staining was significantly weaker in the merozoite of the infected/diclazuril group.

\section{Supplementary Files}

This is a list of supplementary files associated with this preprint. Click to download.

- Riginalimages.docx

- NC3RsARRIVEGuidelinesChecklistfillable.pdf 